\title{
A MINOAN ROUNDEL FROM PYRGOS, SOUTHEASTERN CRETE"
}

\section{Introduction}

This article presents a new roundel from the "country house" at Pyrgos (Fig. 1), inscribed in Linear A and impressed by two seals.

PYR Wc 4 (Ayios Nikolaos Museum 12567) (Pls. 1-4; Figs. 2-8)

Intact and well preserved pentagonal roundel with slightly concave faces. Clay finely levigated with some small whitish inclusions and fired light reddish-brown to a dark brown with many irregular cracks across most surfaces. All surfaces had been smoothed and

The authors would like to thank C. Davaras for his generous permission to publish the roundel; preliminary notices appeared in the American School of Classical Studies Newsletter, Fall 1993, and in Archaeological Reports for 1993-1994, 40, 1994, 82 figs. 71 and 72. A draft of this paper was read by G. Cadogan, E. Hallager, J.-P. Olivier, and J. Weingarten; we are grateful to them all for their enthusiasm and have benefited greatly by their helpful comments. Many of these have been incorporated with the acknowledgment "personal communication". We are also grateful to Ingo Pini who speedily photographed the roundel and its impressions (Pls. 3 and 4 ) and had the drawings (Figs. 7 and 8) drawn in time for their publication here. Any errors that remain, however, are our own.

Abbreviations:

$\mathrm{CMS}=\mathrm{I}$. Pini, et al., eds., Corpus der minoischen und mykenischen Siegel

GORILA = L. Godart and J.-P. Olivier, Recueil des Inscriptions en Linéaire A, Paris $1976-1985$

KSPI = M. A. V. Gill, "The Knossos Sealings: Provenance and Identification", B.S.A. $60,1965,58-98$

PT = Pose Type, as defined in J. G. Younger, The Iconography of Late Minoan and Mycenaean Sealstones and Finger Rings, Bristol 1989, 1-3, a chart.

Illustration credits: The photographs of the roundel (Pls. 1 and 2) are by J. G. Younger, of the impressions (Pls. 3 and 4) courtesy CMS. The plan Fig. 1 courtesy Gerald Cadogan; drawings of the seal impressions (Figs. 7 and 8) courtesy CMS; all other drawings (Figs. 2-6, 9-16) are by P. Rehak. 


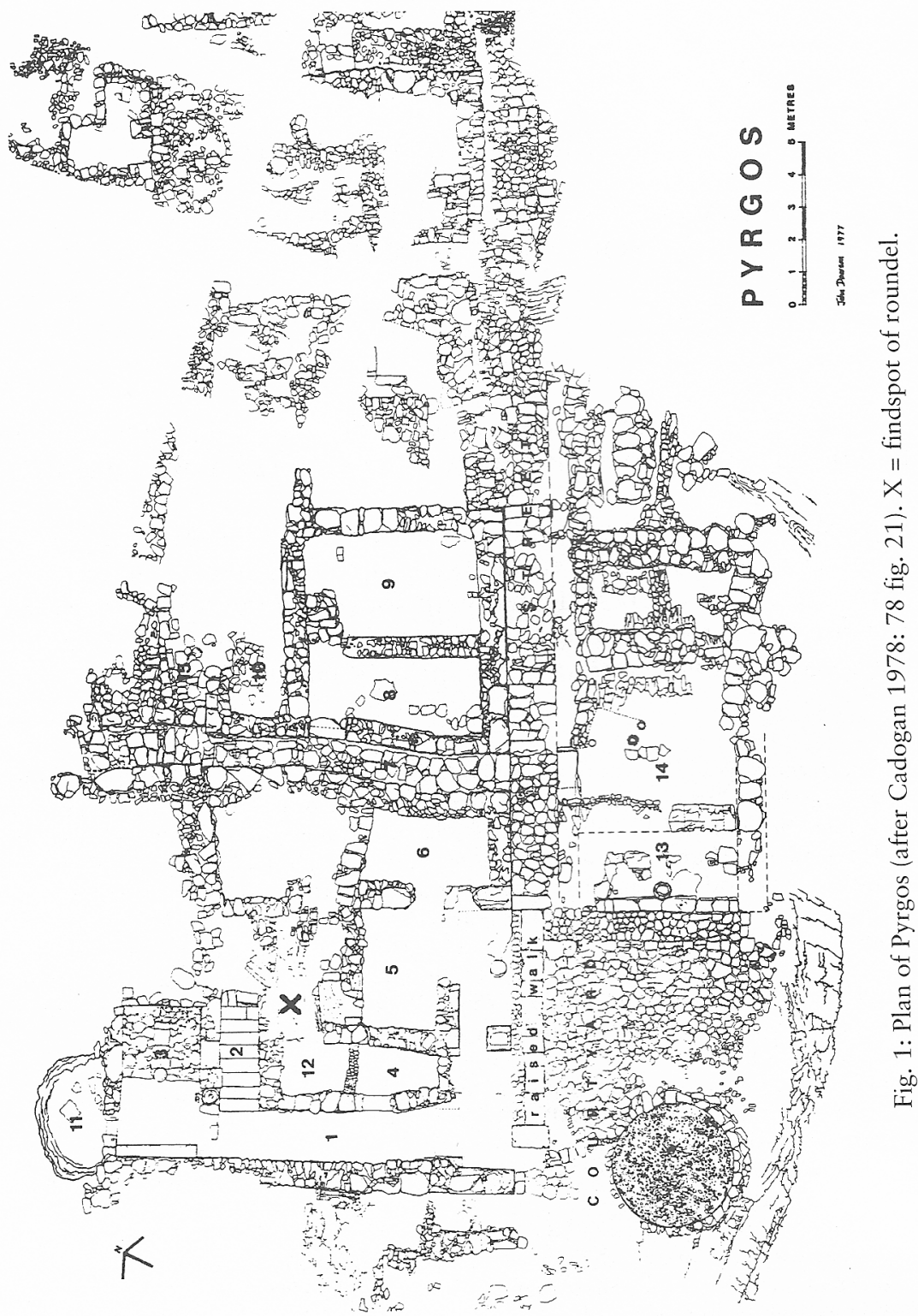


there are abundant traces of fingerprints on both faces and on the ridges between the sides. A characteristic feature of the engraved signs is that they are all firmly and deeply incised, and are generally of a uniform depth, unlike the cracks produced by the conflagration that destroyed the villa and baked the roundel, presumably in LM I B.

H. from base (side $\alpha$ ) to apex $3.0 \mathrm{~cm}$.; W. $2.7-2.9 \mathrm{~cm}$.; Th. maximum $1.2 \mathrm{~cm}$.

Face $\mathrm{A}^{1}$ with long inscription:

$\begin{array}{ll}. \mathrm{A} 1: \mathrm{AB} 37-[.] & \text { L 78-[.] } \\ . \mathrm{A} 2: \mathrm{AB} 28-\mathrm{AB} 41 & \text { L 100-L } 57\end{array}$

Face $B$ with ideogram:

.B: new IDEOGRAM not identified Impressed sides $(\alpha-\varepsilon)$

Sides $\alpha$ and $\beta$ : impressed by a single lentoid $\left(R b ;{ }^{2} R b_{1}\right.$ on face $\alpha$ gives a D. ca. $1.4 \mathrm{~cm}$.) with a single vertical stroke incised across each impression; the impressions depict a bull upside down on its back to right with its head lowered below (a version of PT 13A, L) and two lions antithetic salient above and on the bull (PT 31A); the whole scene being a version of PT 52B.

Sides $\gamma, \delta$, $\varepsilon$ : impressed by a single cushion seal (Rc; metal?; L. ca. $1.3 \mathrm{~cm}$.; W. ca. $0.4 \mathrm{~cm}$.) with a single vertical stroke incised across each impression; the unclear impressions imperfectly preserve a cult scene: left to right, woman, low object, tree(?).

Incisions: a vertical stroke across the middle of each seal impression; if these are read each as the number 1 , then the total 5 should be the number associated with the ideogram. ${ }^{3}$

1 Face A would be called, in conventional epigraphical terms, the recto; and Face B would be called the verso. We will avoid these terms for reasons that will become clear in our section on the manufacture of the roundel.

2 Seal impression $\mathrm{Ra}$ (i.e., the first seal impression found on a Pyrgos roundel) is that on the problematic roundel HMs 1907; see below and fn. 13 .

3 Cf. E. Hallager, "Roundels among Sealings in Minoan Administration: A Comprehensive Analysis of Function", in T. Palaima, ed., Aegean Seals, Sealings and Administration, Aegaeum 5, 1990, 121-142, esp. 127-128. The number of commodities or rations included in the transaction of which the roundel is a record usually corresponds to the number of seal impressions; a more recent discussion of this correlation occurs in M. Perna, "The Roundel in Linear A from Zakro Wc 2 (HM 84)", Kadmos 33, 1994, 29-37, esp. 35-37. 
Total regularized inscription:

according to GORILA:
$\mathrm{AB} 37-[]-.\mathrm{AB} 28-\mathrm{AB} 41$
IDEOGRAM 5

or, in the Evans-Brice numbering system:

L 78-[.]-L 100-L 57 IDEOGRAM 5

Total inscription rendered using Linear B values: ${ }^{4}$

TI-[.]-I-SI

IDEOGRAM 5

\section{The Findspot}

The Minoan site of Pyrgos in southeastern Crete was excavated by G. Cadogan for the British School of Archaeology between 1970 and 1976, and again in 1994;5 as is well known, the site occupies the hill just east of the modern town of Myrtos and consists of a MM town and, on top, a LM I country house that was destroyed by fire in LM I B.

The roundel was a surface find by the authors in August 1993, discovered about $0.5 \mathrm{~m}$. directly east of the southeast corner of the top of the staircase 2 in the country house (Fig. 1: plan marked X). When it was sighted by us, the roundel lay on the ground, ideogramside up, with its surface clean enough for the ideogram to be visible to the naked eye (and, in fact, it was the sign as well as the shape of the roundel, that initially attracted our attention). Slight traces of earth adhered to all sides of the pentagon, and the face with the long inscription was covered with dirt, its linear signs as well as the five seal impressions on the sides entirely obscured until later cleaning revealed them. It thus seems reasonable to conclude that the roundel

4 According to L. Godart, "Du linéaire A au linéaire B", in: Aux Origines de l'Hellénisme: la Crète et la Grèce. Hommage van Effenterre (Paris 1984), 121 128 , the phonetic values of signs DA, I, JA, KI, PA, PI, RO, RI, SE, SU, TA, and O are reasonably secure, possibly also TE, A, KO.

5 For reports on the country house, see S. Hiller, Das minoische Kreta nach den Ausgrabungen des letzten Jahrzehnts, Wien 1977, 160-163 (with summary of preliminary reports in AR and BCH); G. Cadogan, Palaces of Minoan Crete, London 1976, 149-152; idem, "Pyrgos, Crete, 1970-1977", AR 24, 1978, 70-84; idem, "A Probable Shrine in the Country House at Pyrgos", in: R. Hagg and N. Marinatos, eds., Sanctuaries and Cults in the Aegean Bronze Age, Stockholm 1981, 169-171; idem, forthcoming in R. Hagg, ed., "The Function of the Minoan "Villa"". See also W. and E. Myers and G. Cadogan, The Aerial Atlas of Ancient Crete (1992), s.n. Myrtos, pp. 202-209. 
had worked its way up to the surface, or perhaps had washed down from a slightly higher point from the north. It seems not to have belonged to the earth used to backfill and cover the gypsum staircase nearby in the attempt to preserve it.

Since it did not seem prudent to leave this important and fragile document where we had found it, we removed it, cleaned it, photographed and drew it and, the next day, took it to the Ayios Nikolaos Museum where we presented it to the Director, Professor Costis Davaras, who graciously gave us the permission to publish it. Professor Davaras also suggested that the area be cleaned in order to determine if more of the country house's archives still existed. Accordingly, we informed Gerald Cadogan of the new addition to the Pyrgos corpus and asked him to lead a short return season with us as his assistants. This last season lasted from 4 through 22 May, 1994, and while the entire top of the hill was scraped down to bedrock no more documents were found. We were assisted by four of our students: Mark Farmer and Tim Grant of Loyola University, Chicago, and Barbara Olsen and Shane Peterson of Duke University.

That there was an archive at Pyrgos is clear. The findspot of the roundel near the top of the stairs corresponds to the area identified by Cadogan 6 as a possible "house shrine" on the basis of the objects which had been precipitated into the rooms below when the country house was destroyed at the end of LM I B: among these are tubular stands, Marine Style pottery, a fragment of an Egyptian stone vase, and a triton shell of faience along with two real shells. In the same general area were found the country house's administrative items: among destruction debris in corridor 1 a fragment of a Linear A tablet (PYR 1) ${ }^{7}$ recording 90 units of wine; 8 from the area where corridor 1 meets the lightwell 3 the fragment of another (PYR 2) ${ }^{9}$ recording the possible ideogram Linear A 304 followed by the fraction "J". 10 Finally, from the destruction debris over the middle of

Cadogan, op. cit. (supra fn. 5 [1981]).

GORILA 1: 322: Haghios Nikolaos Museum 6524.

8 A. Morpurgo-Davies and G. Cadogan, "A Linear A Tablet from Pirgos, Mirtos", Kadmos 10, 1971, 105-109. According to a private communication from Cadogan (21 August 1993), the tablet was found in a Hellenistic pit dug into the destruction fill.

9 GORILA 5: 59: HM 1681.

10 A. Morpurgo-Davies and G. Cadogan, "A Second Linear A Tablet from Pyrgos", Kadmos 16, 1977, 7-10. 
corridor 1 and the room 12 south of the stairs, 11 two other documents uninscribed but impressed by sealstones: one nodulus ${ }^{12}$ (HMs 1097), which, after some debate, has been identified as an uninscribed roundel (PYR Wc 3) 13 whose seal impression (Ra) shows two lions attacking a bull, 14 and another nodulus (HMs 1098) impressed by a seal that carried the unusual subject of two boars. 15 These administrative records are now on display in the Heraklion Museum, except for PYR 1 which, along with our roundel, is in the Ayios Nikolaos Museum.

Thus, although the roundel was unstratified, it now demonstrates that the Pyrgos country house did indeed produce two types of written documents, tablets and roundels, along with at least one nodulus. In addition, the apparent association at Pyrgos of administrative elements with possible cult equipment recalls on a small scale the discovery of roundels and sealings in the area of the MM III "Temple Repositories" at Knossos. ${ }^{16}$

11 The provenience is recorded in J. Weingarten, "More Unusual Clay Nodules: Addendum II", Kadmos 29, 1990, 16-23, esp. 23 s. no. A-36 and 37.

12 As defined by Weingarten (supra fn. 11), p. 19, a nodulus is "a sealing that does not seal", an independent clay object impressed by a seal and acting like a clay docket (signifying wages) or a token (signifying identity). Noduli do not seal anything, they are not affixed to any object, nor do they hang from any string - they therefore are not sealings in the strict sense of the term.

13 HMs 1907 has received some attention - its form is that of a thick disk of dark coffee-brown clay whose rim received a seal impression. To Hallager it is a thick, uninscribed roundel ("The Use of Seals on the Minoan Roundels", CMS Beiheft $3,1989,55-78$, introductory note [*] and fn. 35; idem (supra fn. 3), 121-134, esp. 139 and 141). But to Weingarten the object was a disk-shaped (unique?) nodulus with the seal impression on the base (supra fn. 11: 22 no. A-37; cf. her comments in Aegean Seals, supra fn. 3, 109 fn. 27). Recently, however, Hallager and Weingarten have agreed that HMs 1907 is an uninscribed roundel (Hallager, personal communication).

14 The seal was probably a lentoid and should be placed close to the Mycenae-Vapheio Lion School or the Almond-Eye Group (J. G. Younger, "Aegean Seals of the Late Bronze Age: Masters and Workshops, III. The First-Generation Mycenaean Masters", Kadmos 23, 1984, 39-64). The attack scene can be identified as PT 51D, R.

15 HMs 1098 is a prismatic nodulus of light chocolate-milk brown clay with one side impressed by a lentoid with two boars in PT 23A, R, the near boar with its head down in PT 1B overlapping the far boar with its head up in PT 1C; the style of the seal seems close to the Group of the Brommer Sow (J. G. Younger, "Aegean Seals of the Late Bronze Age: Masters and Workshops. IV. Almond- and Dot-Eye Groups of the 15th Century B.C.", Kadmos 24, 1985, 64).

16 E. Hallager, "The Knossos Roundels", B.S.A. 82, 1987, 55-70; M. Panagiotaki, "The Temple Repositories of Knossos: New Information from the Unpublished Notes of Sir Arthur Evans", B.S.A. 88, 1993, 49-92. 


\section{General Characteristics}

As an inscribed roundel PYR Wc 4 falls into Hallager's fourth category 17 : "two-side inscriptions with a single sign on one side and a sign group on the other side". With the seal impressions, the roundel joins the small group of now eight MSI (multi-seal-impressed) roundels. 18 The crisp pentagonal shape of our roundel is unusual; the best parallel is GO Wc $1^{19}$ from room Cf 25 at Gournia (the northeastern corner of the excavated site); it is similarly inscribed on both faces and has all five sides impressed, though all by the same lentoid whose design apparently consisted of a quadruped, probably a bull, standing left with its head down. ${ }^{20}$ From Knossos come two more crisply pentagonal roundels, both, however, uninscribed: KN Wc 44 was stamped on all its five sides with a single lentoid that carried a lion attacking a bull from above, ${ }^{21}$ while KN Wc 41 had its sides impressed by four different seal faces, 22 at least two of which, Hallager's Rh and Ri, ${ }^{23}$ probably come from the same four-sided prism with rectangular faces. ${ }^{24}$

The size of roundels seems to have been pre-determined by the number of seal impressions the scribe was to make on the sides. ${ }^{25}$ Generally, the scribe prepares a disk of clay and, according to Hallager, 26 impresses the edge with the seal(s); in so doing, the scribe

17 E. Hallager (supra fn. 13): 67, table of inscriptions on p. 69.

E. Hallager (supra fn. 13): 55 fn. 1 and Table 1; idem (supra fn. 3): 135 Table 1, last column lists 6 roundels impressed by more than one seal: the six earlier roundels were KN Wc 3, 30, 41 and 46 [cf. Hallager, supra fn. 16]; and MA Wc 13 and 14. The seventh roundel comes from Mikro Vouni, Samothrace, SA Wc 2 impressed by four different seal faces, CMS V Supp. 1B impressions nos. 322-325 (a second roundel Wc 1 carries four impressions of one seal CMS V Supp. 1B 326). See also D. Matsas, "Samothrace and the Northeastern Aegean: the Minoan Connection", Studia Troica 1, 1991, 159-179. Both roundels should date contemporary with MM II according to the styles of their imprcssions.

19 H. Boyd Hawes, Gournia, Philadelphia 1908, 55, pl. XXVI AND fig. 31 a, b. Diameter $3.5 \mathrm{~cm}$; thickness $0.8 \mathrm{~cm}$. Hallager (supra fn. 13): 70 and fig. 11 and fn.

35. GORILA 2: 2 .

20 Cf. W. C. Brice, Inscriptions in the Minoan Linear Script of Class A, Oxford 1961, 19, III 10.

21 KSPI O3. Hallager (supra fn. 16): 61, fig. 1.

22 KSPI L16/17 and L45.

23 Hallager (supra fn. 13): 73 , fn. 35 .

24 Hallager (supra fn. 16): 59-61, fig. 2.

25 Hallager (supra fn. 13): 61 and 65.

26 Hallager ibid., 71, and personal communication. 
creates the shape of the roundel. ${ }^{27}$ Roundels that have two seal impressions next to each other (e.g., KN Wc 23) 28 have two defined edges separated by a ridge while the rest of the rim retains what is left of the original circular shape; roundels that are impressed five times have a pentagonal shape; and roundels that are impressed many times have polygonal or indented shapes (e.g., KN Wc 25 and 45).29

The pentagonal shape of PYR Wc 4 seems to us, however, not to have resulted solely from the act of impressing. Since the clay was already hard enough to resist spreading out under the seal as it was pressed into the clay, then the seals could not easily have dented the edges; and had the roundel had a purely convex rim at the outset, we would have expected to see the sharp vertical edges that the seal's rim cut as it sank into the clay - only the left edge of the cushion made such a cut as it sank close to the ridge that separates the edges. Finally, if the scribe took the number of eventual seal impressions into account when adjusting the size of the roundel, it seems logical to us that the scribe may also have prepared the edges in advance, shaping the roundel into its pentagonal form - not to have done so, it seems to us, might have risked uneven placement of the seal impressions and a resulting inelegant polygonal form (contrast KN Wc 26 [CMS X 120], whose lumpy shape comes from haphazard seal impressing, with KN Wc 23 with its neatly pinched form).30

\section{Face A with the long inscription (Pl. 1, Figs. 2, 3)}

The first sign in line 1 is a well-attested variant on sign AB $37(\mathrm{~L}$ 78 ), with the addition of a short vertical stroke between the legs. Good parallels for the sign inscribed in this manner not only exist at Pyrgos itself (PYR 1.1) ${ }^{31}$ but also elsewhere, for example on incised

27 Olivier, personal communication, agrees: as with GO Wc 1 , it is the act of impressing "ce qui lui donne son aspect 'pentagonal' comme à sa sœur de Myrtos".

28 Hallager (supra fn. 16): 57, fig. 1.

30 Both are illustrated in Hallager ibid., fig. 1.

31 Sign 37 on both our roundel and PYR 1.1 exhibits strikingly similar elements: a uniformly curving left leg (in the photograph of PYR 1 , not the drawing) contrasting with the right leg, which begins with a sharp curve which is angled into a gentler one about a third of its length from the top. The legs are of uniform length, stopping precisely level with each other. The short vertical dash between them is precisely positioned just under the top of the right leg (note how the right leg in both documents begins just under the top of the left leg), slightly to the right of center, and exactly one-third the height of the entire sign. 


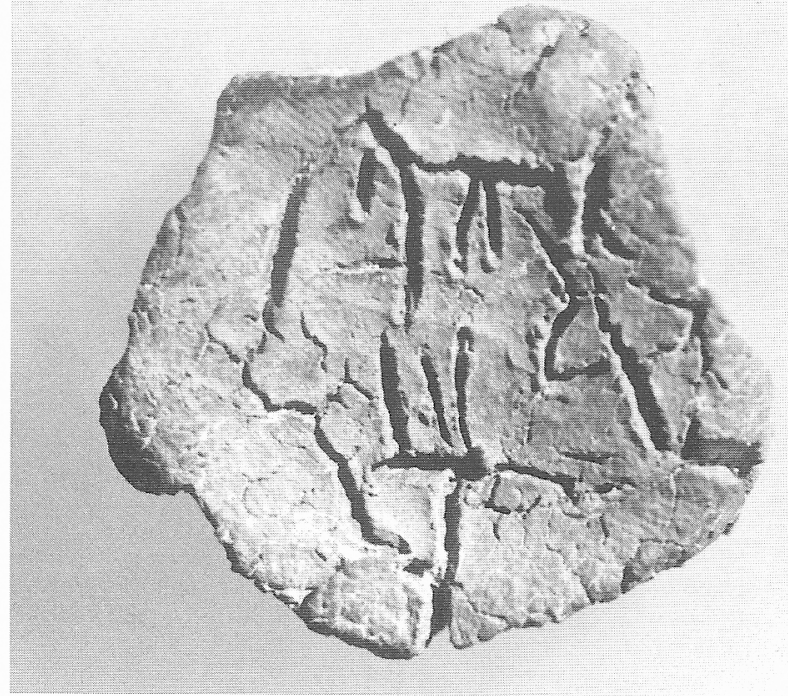

Pl. 1 Face A with long inscription (scale 2:1; photo J. G. Younger)

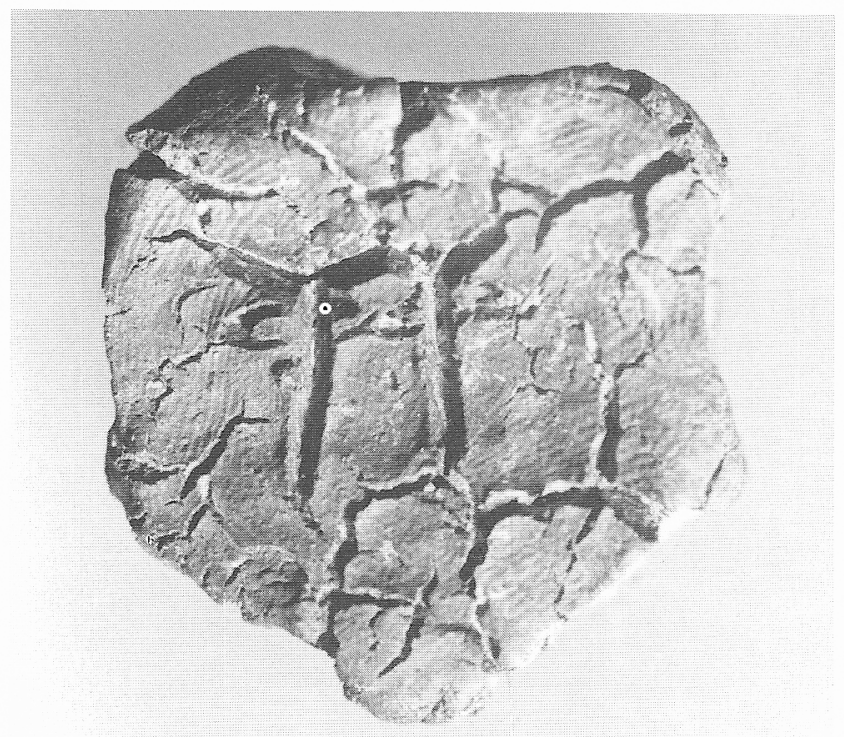

Pl. 2 Face B with the ideogram (scale 2:1; photo J. G. Younger) 


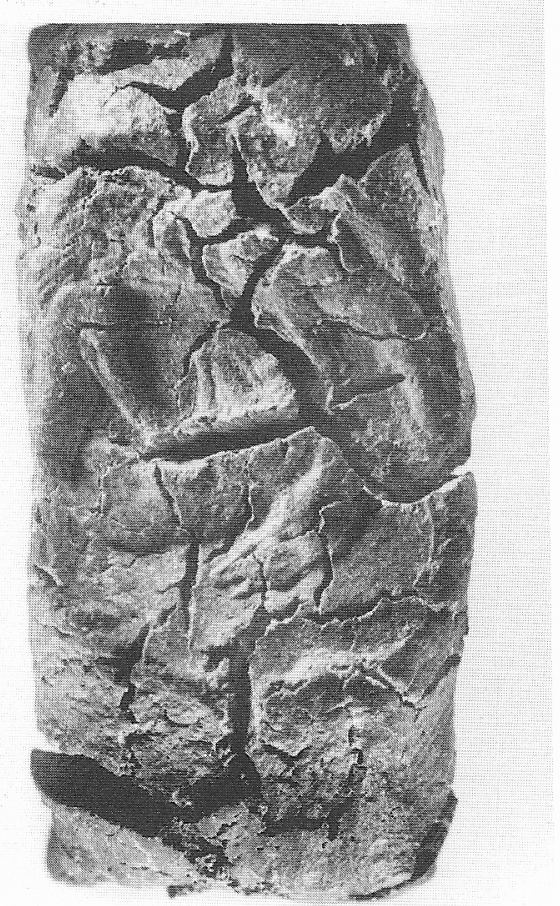

Pl. 3 Side $\alpha$ : lentoid impression (scale 3.7:1; photo CMS)

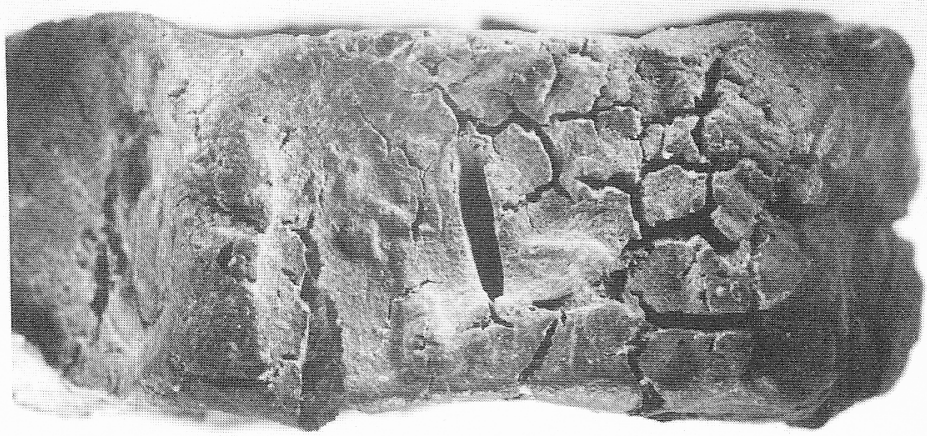

Pl. 4 Side $\gamma$ : cushion impression (scale 3.1:1; photo CMS) 


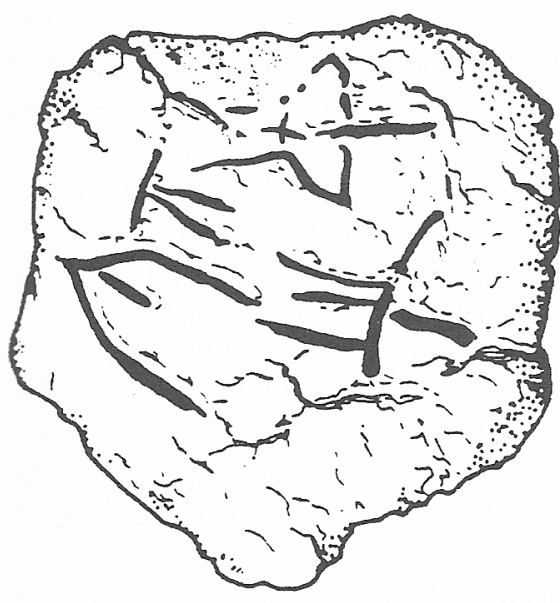

Fig. 2: Long inscription on face A (drawing P. Rehak).

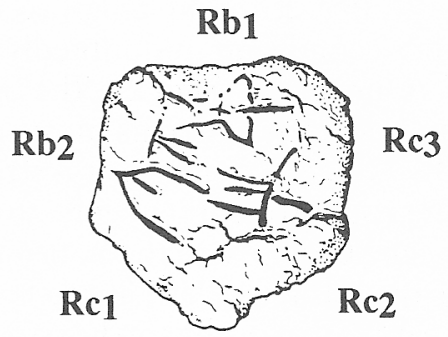

Fig. 3: Roundel diagram: orientation of inscription to impressed sides (drawing P. Rehak).

metal pins: one of gold of unknown provenience now in the Ayios Nikolaos Museum, CR (?) Zf 1 (GORILA 4: 146), a second of gold from Mavro Spelio, KN Zf 31 (GORILA 4: 154), and a third of silver from Platanos, PL Zf 1 (GORILA 4: 161), these last two now in the Heraklion Museum.

The second sign on face A line 1 is now badly preserved and cannot be read securely. What has survived consists of a deeply engraved horizontal dash above two shorter vertical lines that converge at their tops where they join the underside of the horizontal dash, and possibly two other lines, an oblique, slightly wobbly stroke at the right, and, below, another oblique line that seems to join the top of the inscription's last sign AB 41 ( $\mathrm{L} \mathrm{42}$ ).

For the second sign the only sure strokes that survive are the first three, the horizontal with the two verticals below. Few signs contain this element: AB 51 (L 93) 32 which would then have to have been written backwards (as, apparently, on KN Zf 31) and without its characteristic loop above; candidates even more remote might be AB 118 (L 85) and A 342 (L 144). Another remote possibility is that

32 Hallager, personal communication. 
the three strokes at the left might be a uniquely written number 12 , the horizontal being the 10 and the two verticals below adding 2.33

In line 2, the first sign seems definitely to be AB 28 (L 100) and the second sign undoubtedly is $\mathrm{AB} 41$ (L 57).

Our scribe's sign 28, the first sign in the second line, is formed in an odd way. Whereas most scribes seem to form the double base of the "fingers" with several strokes, ${ }^{34}$ going first from left to right for the top stroke, then right to left for the bottom stroke, the Pyrgos scribe begins with the bottom stroke, far to the right side. The stylus is then dragged left; at the left end, the stylus doubles back over the stroke as if for the top horizontal and digs in deeply to end the stroke just under the right vertical "finger" of the sign. Here, the stylus has gouged up a dot of clay, which obscures the beginning (right) side of the horizontal stroke of the sign.

The second sign in line 2 is undoubtedly AB 41 (L 57); at the right the sign is faint, having been smudged by the scribe's finger, and the oblique stroke[s] above probably belong to the second sign in the top line. The precise form of the sign finds similarities again in PYR 1, the third sign $A B 26$ (L 55): though the long vertical middle stroke differentiates the two signs, we again notice its precise placement and the similarly precise symmetry and control of the curves.

The total long inscription, then, reads: AB 37-[.]-28-41 (L 78-[.]L 100-L 57). No intact word in the Linear A corpus matches this, but there are three broken words ending in AB]-28-41 (L]-100-57):

$\mathrm{AB}$

KH 9.3: ]28-41,

KH 51.1: ]41-28-41

KH 16.2: ]10-59-28-41 $624(=303+\mathrm{D})$

Evans-Brice

$\begin{array}{ll}1100-57 & 71+\mathrm{D} \\ 157-100-57 & 3 \\ 197-74-100-57 & 71+\mathrm{D}\end{array}$

33 Sign 37 occasionally acts as an ideogram preceding numbers: on an incised MM III B pot from Knossos, KN Zb 5 (HMp 2600; GORILA 4: 76], Zakros tablet ZA 12.1 [GORILA 3: 176]; and on PK 1.1 [GORILA 1: 280]. If the second sign on our roundel was the number 12 , the scribe, an insistent left-to-right writer, would have written his 10 first, then the two strokes for 2 below, adding them together, as it were. Although such a form for the number 12 would be unique, we might recall the unusual way the number 90 was written on PYR 1.2, with the ninth dash at the bottom of the second column, not, as is usual, at the bottom of the first column (GORILA 1: 322: "la dernière dizaine est certaine bien que dans une position inhabituelle").

34 E.g., HT 55 b.2: GORILA 1: 106-107. 
What the word AB 37-[.]-28-41 means is, of course, unknown, but as a hapax legomenon it is likely to be a personal name or local toponymn, and the -41 ending may signify an objective ("to" or "from"): "to/from so-and-so/such-and-such".

\section{Face B with the ideogram (Pl. 2, Figs. 4, 5)}

When oriented upright, the single large sign deeply engraved onto the surface of face $B$ is located slightly to left of the center, and the wide base of the pentagonal roundel appears at the top and its apex points downward.

The sign consists of a nearly parallel pair of vertical strokes, surmounted and joined by four oblique strokes which form a "W" across the top. Flanking each of the parallel uprights near its top is a pair of short curvilinear strokes resembling "Cs", arranged antithetically in a mirror-image pattern so that the opening of each " $\mathrm{C}$ " faces the upright that bisects the pair. These uprights diverge slightly from one another at the bottom, and each terminates with a slight curve to the right.

No published Linear A sign corresponds closely to ours.

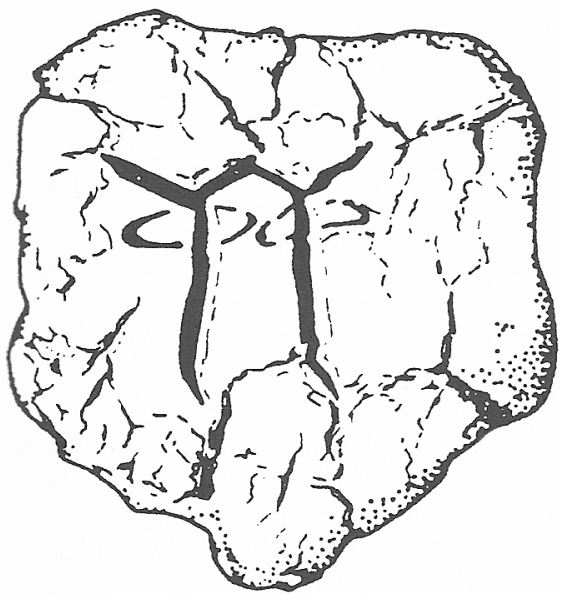

Fig. 4: Ideogram on face B (drawing P. Rehak).

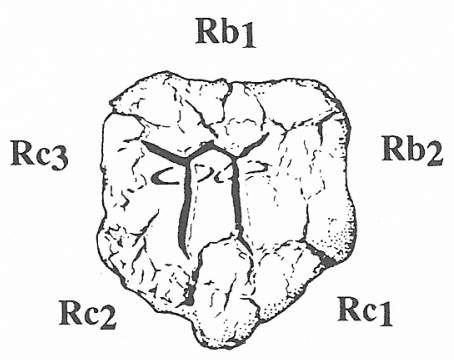

Fig. 5: Roundel diagram: orientation of inscriptions to impressed sides (drawing P. Rehak). 
If a pictogram, the sign resembles a bovine face, open below at the neck, as if conveying the form of a bull-head rhyton. If an ideogram, the sign's linear profile, the horizontal lines that form a Wshape at the top and the vertical legs that support it, looks like a variant of sign $A B 45^{35}$ though that sign's vertical stroke in the middle is missing here (as on CR(?) Zf 1, last sign; GORILA 4: 146-7) and so is its invariably present horizontal base in the triangle at the top (unless the two addorsed interior Cs vary this stroke). Hallager (personal communication) proposes a doubling of A347 (cf. B AURUM), although the two horizontal strokes at the right of that sign are missing here and a doubling of a commodity usually weighed in discrete units makes no immediate sense; if it is a doubled sign, Olivier (personal communication) prefers a doubling of $A B$ 120+120 (cf. B GRANUM).

If one concentrates on the $\mathrm{Cs}$, the ideogram stands a slight chance of being a version of $\mathrm{AB} 164$. GORILA takes this sign to consist, in its standardized form, of an upright rectangle with two Cs inside, back to back like two interior vertical mug handles. ${ }^{36}$ As such, this ideogram appears once on a tablet and three times on Khania roundels; 37 but one variant resembles ours in that it has no bottom horizontal stroke. 38

We would emphasize, however, that our sign resembles no other sign closely and may in fact be a new ideogram; we leave the final designation of this sign to others.

35 Olivier, personal communication.

36 Linear $B * 164$ adds another pair of addorsed Cs hugging, as it were, the top and the bottom of the mug.

37 HT 17.1: GORILA 1: 34-35. KH Wc 2042 (here with an added oblique line at the left and an upraised continuation of the left vertical stroke), 2043, and 2044: GORILA 3: 129-130.

38 Again once on KH Wc 2044: GORILA 5: 46. Two other variants consist again of an upright rectangle, once with an " $\mathrm{X}$ " inside (HT 19.1: GORILA 1: 36-37) and once with the interior addorsed "Cs" but no bottom horizontal stroke. Though these two forms, the one with the "Cs" and the other with the "X", are really quite different they have been given the same number *164a, presumably because, in the Ayia Triada tablets, they both occur as (phonetic ?) signs in the middle of the same word: 60-164a-37 (apparently a heading modified by the 'branch' sign, 04, that records quantities of "131a VINUM). All the other occurrences of 164 occur as variants ("164b-d) and only on Khania roundels (GORILA 3: 128-130). Since no other inscription appears on these roundels and the object that lies behind the renderings now known as $* 164$ a-d remains obscure, it is impossible to know precisely what $* 164$ is meant to represent. 


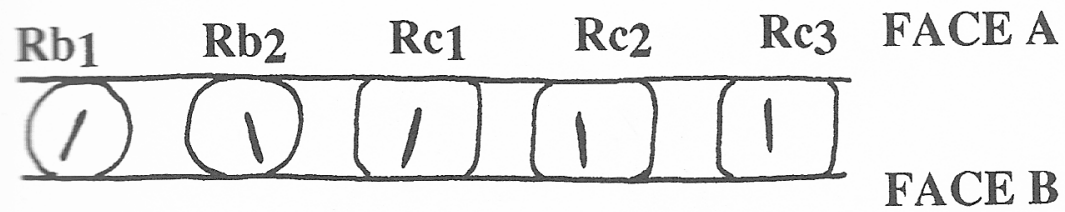

Fig. 6: Roundel diagram: orientation of impressions to faces (drawing P. Rehak).

Impressed Sides $\alpha-\varepsilon$

Each of the Pyrgos roundel's five sides is impressed by a seal, a lentoid impressing sides $\alpha$ and $\beta\left(\mathrm{Rb}_{1}\right.$ and $\left.\mathrm{Rb}_{2}\right)$ and a cushion impressing sides $\gamma, \delta$, and $\varepsilon\left(\mathrm{Rc}_{1}, \mathrm{Rc}_{2}, \mathrm{Rc}_{3}\right) .39$

The orientations of the seal impressions to the roundel (Fig. 6) reflect how the scribe held the seals (Figs. 11, 12, 14), pinching the ends of their string together at the back and orienting the seals so that the stringhole paralleled the faces of the roundel. Thus, the vertical stringhole of the lentoid and the composition on it parallel the faces, as does the horizontal stringhole of the cushion, while its composition, however, is oriented perpendicularly to the faces.

None of the seal impressions can be identified with ease, and only a few details of the composition of the cushion used to impress sides $\gamma, \delta$, and $\varepsilon$ can be made out. As a result, the CMS drawings published here are composites based on an examination of all the impressions; they are reconstructions rather than direct renderings, and must be used with caution.

\section{The lentoid, Rb (Pl. 3; Fig. 7)}

The small lentoid (D. preserved $1.4 \mathrm{~cm}$.) stamped sides $\alpha$ and $\beta$. Its design can be almost entirely reconstructed; the composition is unique, combining two elements. A bull, with head regardant and contorted upside down over its back (PT 1D, L), is itself turned upside down (belly up, head thus below); its forelegs are folded under it, appearing therefore above the belly; missing are most of the tail and both hindlegs. Two lions stand antithetic and rampant on and above the bull, their forelegs resting on the bull's belly and chest, their hindlegs stretched down and out to the rim of the seal; the head

\footnotetext{
As will be made clear later, the cushion seal impressed the roundel first, first stamping side $\delta$, then $\varepsilon$, and finally $\gamma$; then the lentoid stamped side $\beta$, then $\alpha$ : so, $\operatorname{Rc}_{2}$, $\mathrm{Rc}_{3}, \mathrm{Rc}_{1}, \mathrm{Rb}_{2}, \mathrm{Rb}_{1}$.
} 


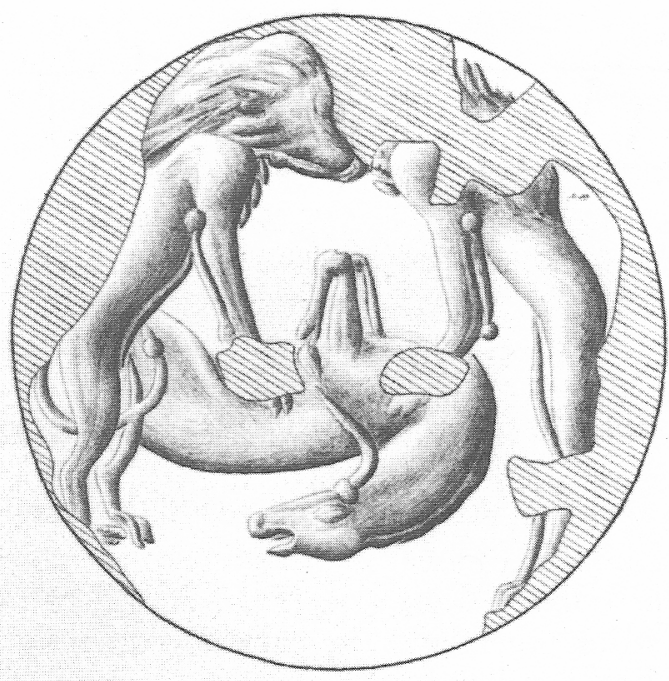

Fig. 7: Lentoid Rb (drawing CMS).

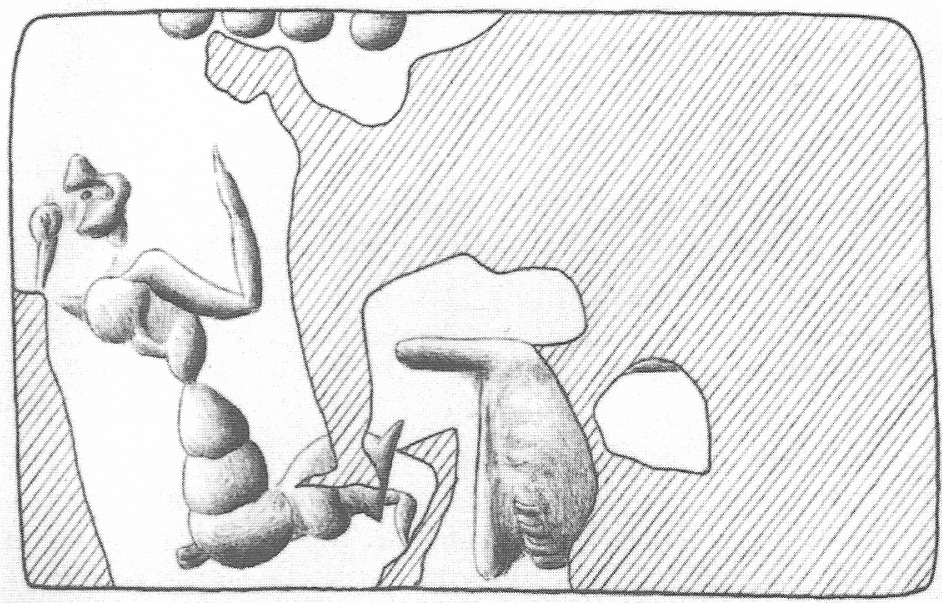

Fig. 8: Cushion Rc (drawing CMS). 
of the left lion is visible and may have obscured the other lion's head. The composition as a whole corresponds to PT 52B, "Two Attackers Stand Salient and Antithetic over Victim", 40 except that the victim is upside down. Our impressions were made by the third seal known to carry this composition, the other two being CMS I 81 (with two dogs over a stag), and V 596 (with two griffins over a quadruped [bull?]).

The rampant pose of the lions is well known not only on seals (e.g., CMS I 46) but also in other media like the Mycenae Lion Gate Relief. The contorted pose of the bull, his head upside down over his back, is rare (PT 1D) and the upside down orientation is unique. The folded forelegs find a good parallel, however, on CMS I 63 where it folds below the bull's belly (cf. CMS VII 157 and XI 226).

As for style, the thick upper forelegs of all three animals flanked by parallel profile lines, the bull's distinctly almond-shaped eye, the profile line alongside the lions' bellies, their bosslike shoulders and dotted ulnas, and the general sensitivity to mass, are all characteristic traits of the "Mycenae-Vapheio Lion School" (LM I B/LH II A). ${ }^{41}$

The best preserved detail in the impression is the bull's head with open mouth and square nose in shallow relief (cf. the lion on CMS V Supp. 1A 3 from the Aphaia Temple, Aigina). The delicacy of carving here allows us to imagine the fine quality of the original small seal which must have been of hard stone.

The cushion seal, Rc (Pl. 4; Fig. 8)

The cushion seal (L. ca. $1.4 \mathrm{~cm}$.; W. ca. $0.9 \mathrm{~cm}$.) apparently carried a cult scene along its long axis; the stringhole is therefore horizontal (see below), and the string is actually visible cutting across the ridge from side $\gamma$ to side $\beta$ and from side $\varepsilon$ cutting halfway across side $\delta$. A woman stands at left, probably facing right, her arms held out to either side and bent up at the elbow. Immediately in front of her, in the middle of the seal, is something low but indistinct, perhaps a kneeling figure, a double omphalos, or an architectural construction. ${ }^{42}$ At the extreme right there may have been another ele-

Younger, The Iconography of Late Minoan and Mycenaean Sealstones and Finger Rings, Bristol 1989, pp. 116-117.

41 Younger 1984 (supra fn. 14): 46-49, 56.

42 K. Krattenmaker, "Architectural Representation: A Clue to its Place in Minoan Society”, AJA 95, 1991, 291 (abstract). 
ment that connected with the blobs at the upper center, perhaps a tree growing from the right rim up and left.

The use of cushions to impress roundels is extremely rare; other than ours, only one other roundel, KN Wc 25 (uninscribed), was impressed by a cushion seal (KSPI L47), in that case eight times. ${ }^{43}$

A few cult scenes appear on cushions, but these involve a single figure with cult equipment or a presumed sacrificial animal. A woman with sword and "lustral sprinkler" from Knossos (CMS II3 16), ${ }^{44}$ a woman with a griffin rampant before her from Tiryns (CMS V Supp. $1 \mathrm{~B} 429), 45$ and a man in front of an altar from Naxos (CMS I 608), all appear on cushions with vertical stringholes, as one would expect for such special scenes; 46 our cult scene on a cushion with a horizontal stringhole is unique.

The cult scene on the cushion that impressed our roundel, however, belongs to a type (a standing woman, something low in the center, and a tree) common on rings; ours is the only cushion. The closest parallel occurs on a sealing from Ayia Triada (AT 138, HMs $523),{ }^{47}$ with, from left to right, a woman, two omphaloi, and a tree. Other rings incorporate elements in common with our cushion: a woman and a tree on CMS II3 15 (the tree grows from a shrine at right); compare the lentoid XII 12D with a woman saluting the tree. Several variants also exist. Thus, CMS V Supp. 1A 178 and another Ayia Triada sealing (AT 137, HMs 576) 48 both present two women flanking a tree; and CMS II3 105 and XI 28 both add a man to the scene.

As for style, the impressions preserve little that can be considered diagnostic; only the woman at left appears at all clearly. She seems to be made of simple forms with oval blobs for the head and elongated ovals for body and arms; so too the foliage (if that is what this

43 KN Wc 25: Hallager 1987 (supra fn. 16): 57, fig. 1, 63 Table 1.

44 For discussion, see P. Rehak, "New Observations on the Mycenaean 'Warrior Goddess", AA 1984, 535-545.

45 P. Rehak, "Tradition and Innovation in the Fresco from Room 31 in the 'Cult Center' at Mycenae", in: EIK $\Omega N$, Aegaeum 8, 1992, 39-62, esp. 57, pl. 19c. The cushion seal, of agate, is a re-cut bead with three grooves on the reverse, corre-

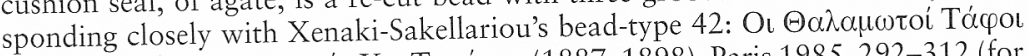

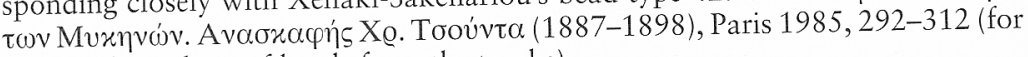
a general typology of beads from the tombs).

46 J. G. Younger, "Non-Sphragistic Uses of Minoan-Mycenaean Sealstones and Rings", Kadmos 16, 1977, 141-159, esp. 153-157.

47 D. Levi, "Le cretule de Haghia Triada", ASAtene 8-9, 1929, 7-156, esp. 140.

48 Levi (supra fn. 47): 139. 
is) at the top center. If these ovals constitute diagnostic traits then it is possible that we have the impression of a gold or gilded cushion that belonged to the LM I Isopata and related Ring Groups. ${ }^{49}$

\section{Observations on the Manufacture of the Roundel (Figs. 9-16)}

The roundel's well prepared fabric and its carefully prepared and produced shape, the five seal impressions made by two seals and then incised, and the two different inscriptions, all bespeak a complex process. In the little time that we had the roundel in our possession we worked intensively to recover the scribe's process of forming the document, shaping, inscribing, and impressing it. We think we have come close to reproducing this process, which we summarize here and in illustrations (for the parts of the roundel, see Figs. 3 and 5):

1) Since the pentagonal shape creates an automatic orientation with the apex (point between sides $\gamma$ and $\delta$ ) either up or down, and since only the ideogram on face $B$ respects this orientation, making the point down and putting the flat "base" (side $\alpha$ ) at the top, and since the cushion impressions are so oriented that when they are read upright, both faces are horizontal, we assume that the scribe had both the pentagonal shape and the two faces deliberately in mind, especially face B, when the impressions were made (Fig. 9).

2) As the discussion about the formation of sign 37 implied (see fn. 31), the scribe was right-handed; so we assume the roundel was held in the left hand, ideogram on face $B$ facing the scribe, and the stylus in the right (Fig. 9).

3) To impress the edges, it would be most natural to hold the roundel's faces between fingers and thumb of the left hand and im-

For a general presentation of these groups, see J. G. Younger, "Aegean Seals of the Late Bronze Age: Masters and Workshops, II. The First-Generation Minoan Masters", Kadmos 22, 1983, 134-135.

Only four gold cushions and evidence for two gilded cushions survive; none carries a cult scene. Three gold cushions come from Mycenae shaft grave III: CMS I 11 is a little larger than our reconstructed cushion $(1.2 \times 1.8 \mathrm{~cm}$.); two others (CMS I 9 and 10) are larger still $(1.5 \times 2.0 \mathrm{~cm}$. and $1.5 \times 2.5 \mathrm{~cm}$., respectively). The fourth gold cushion, CMS I 293 from Pylos, is the largest of all $(2.1 \times 2.7$ $\mathrm{cm}$.). One gilded cushion comes from Palaikastro (V. E. G. Kenna, Cretan Seals, no. 203), and CMS IV 39D presents the presumed gold covering for a lost cushion seal. There are also gilded lentoids (CMS V 197 and IX 204). For a general discussion of such gilded seals, see J. G. Younger, "The Lapidary's Workshop at Knossos", B.S.A. 74, 1979, 258-268, esp. 265-266. 
press with the right - thus the faces are slightly concave. But since the signs on both faces are not obliterated, we can assume the seal impressions were made first, before the inscriptions.

4) Since the string of the cushion seal runs from side $\gamma$ over the ridge toward side $\beta$ (Pl. 3), we assume $\gamma$ was impressed $\left(\mathrm{Rc}_{1}\right)$ before $\beta\left(\mathrm{Rb}_{2}\right)$, whose impression obliterated further traces of the string there; similarly, since the string of the cushion seal runs from side $\varepsilon$ half way across side $\delta(\mathrm{Pl} .4)$, we assume that $\delta$ was impressed $\left(\mathrm{Rc}_{2}\right)$ before $\varepsilon\left(\mathrm{Rc}_{3}\right)$, whose impression involved the string being imbedded into the already impressed side $\delta$.

5) Between sides $\gamma$ and $\delta$ lies the apex of the roundel's pentagonal shape, and thus the scribe began two series of impressions beginning outward from that point. Since the left end of $\delta$ is squeezed by the impressing of $\gamma$, we assume that the sequence ran as follows: $\delta$ first and $\varepsilon$ second; then $\gamma$ third and $\beta$ fourth (side $\beta$ has the clearest impression of all). 50

6) Such a reconstruction means that side $\alpha$ was impressed last.

7) Then the ideogram was inscribed, keeping its upright orientation.

8) Finally, the roundel was flipped over and the long inscription was inscribed in such a way that the face has an oblique orientation that must reflect the way the roundel was held rather than the shape of the roundel's face.

9) To reproduce this sequence of actions easily, we assume that the scribe began by holding the roundel between the middle finger and the thumb of the left hand, the middle finger on the ridge $\varepsilon \alpha$ and the thumb on the point $\gamma \delta$ (Figs. 9 and 10 ), and that she ${ }^{51}$ used the fourth finger on point $\alpha \beta$, to turn the roundel first so that face $B$ faced down (swiveling it between thumb and index finger) and then up to inscribe the long inscription (Fig. 15).

- First, she turns face B away (Figs. 10 and 11), with sides $\delta$ and $\varepsilon$ towards her: she then impresses side $\delta$, then $\varepsilon$;

50 Hallager has also examined the roundel and concluded a slightly different and straightforward order of impressing (personal communication): $\varepsilon, \delta, \gamma, \beta, \alpha$.

51 In the following discussion we shall use the feminine pronoun for the scribe, mainly because we know that more women than men are depicted wearing sealstones. For the most recent discussion of representations of sealstone-wearers, see P. Rehak, "The Aegean 'Priest' on CMS I 223", Kadmos 33, 1994, 76-84, esp. 78; cf. J. G. Younger, "Bronze Age Representations of Aegean Bull-Games, III", ПO Aegaeum 12, vol. 2, 507-545, esp. 517 n. 38. 


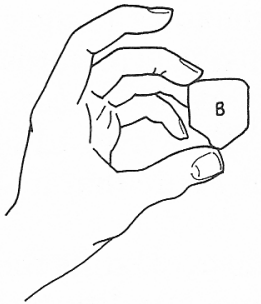

Fig. 9: Holding the roundel

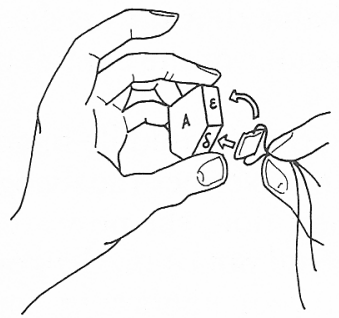

Fig. 11: Impressing sides $\delta$ and $\varepsilon$

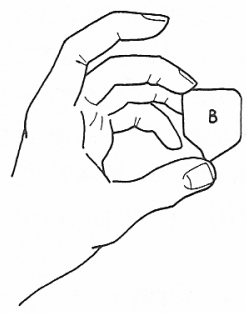

Fig. 13: Holding the roundel ready to receive the lentoid impressions

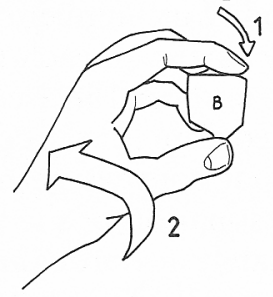

Fig. 15: Holding the roundel for inscribing the ideogram and ready to turn it over

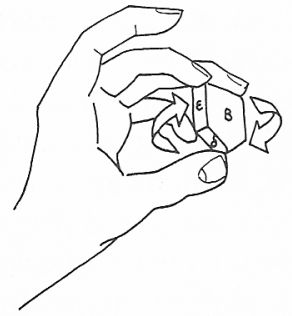

Fig. 10: Turning the roundel over from face $B$ to face A

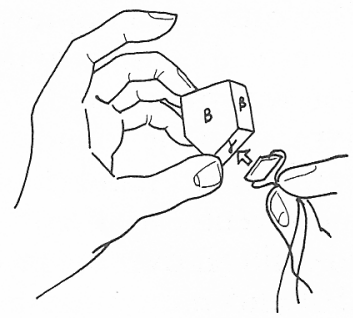

Fig. 12: Impressing side $\gamma$

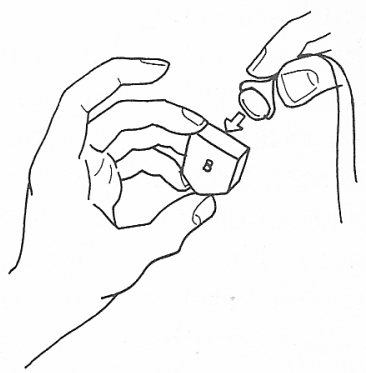

Fig. 14: Impressing side $\alpha$

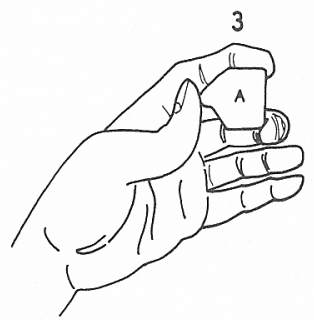

Fig. 16: The roundel turned over for inscribing the long inscription

(All drawings P. Rehak). 
- second, she reverses the action: using the fourth finger on point $\mathrm{AB}$ to nudge the verso to turn back, with side $\gamma$ towards her; she turns her right hand over to make sure the cushion seal reads upright with respect to face B and impresses side $\gamma$ (Fig. 12).

- third, she changes to the lentoid, making sure that its base also orients to face B and impresses side $\beta$.

- fourth, to get a clear impression on side $\alpha$, she tilts the roundel forward, slightly away from her middle finger and turns her right hand clockwise to produce a firm impression, and impresses side $\alpha$ (Fig. 14).

- fifth, after each impression, it is probable that she marked each with a vertical incision to denote that one unit of the commodity in question was transferred.

- sixth, with the roundel still held between the middle finger and thumb of her left hand (Fig. 15), the scribe inscribes the ideogram.

- and seventh, to inscribe the long inscription, she now stretches her index finger over the face of the verso and puts it on the point $\alpha \beta$ (Fig. 16) and rotates her hand at the wrist one half turn counterclockwise. Face $\mathrm{A}$ is now towards her and the finished long inscription will be upright.

In this entire procedure, the fingers have held the roundel by points $\varepsilon \alpha$ and $\gamma \delta$ - these are the most severely blunted. The index finger has used the ridge $\delta \varepsilon$ to turn the roundel in the second step - this ridge too has seen pressure; and the index finger has used the ridge $\alpha \beta$ to turn the roundel over to inscribe the long inscription - this ridge too is blunted. The only ridge not touched in this reconstruction is $\beta \gamma$ and this one retains its sharp edge.

We would emphasize that this procedure - when put into words sounds more complicated than it is in practice. Conceptually, the process is simple: first, the scribe shapes the roundel with a number of sides equal to the amount of the commodity or number of transactions; then, the transactions are actually finalized, each transaction certified by a single impression and the number 1 incised across it; finally, a description, starting with the ideogram for the commodity itself and, on the other side, a word that conveys perhaps the commodity or more likely the origin or destination of the transaction, whether place or person. Even a moderately dexterous and practised scribe could have stamped, incised, and inscribed both faces in less than a minute. Such a transaction, obscure as it now seems to us, might have been quite routine to the Minoan writer. 
One question remains: how many individuals were involved in the inscribing of the roundel? 52 Conceivably there could have been as many as four, if one was the scribe who made the roundel and wrote the linear inscriptions on both faces; the second and third individuals would have been the two seal-owners, if these are different people; and a fourth could be the person who incised the strokes across the impressions (if this were not done by the scribe). We consider three the likeliest number, however: the scribe along with two seal-owners. ${ }^{53}$ The fact that so few surfaces are obscured suggests that it was the scribe who actually held the roundel throughout the transaction, impressing and incising the sides and writing on the faces, as shown in our drawings (Figs. 9-15).

\section{Summary and Conclusions}

Despite its status as a surface find, the pentagonal roundel from Pyrgos makes this site an important addition to those nine locations that have previously produced roundels: ${ }^{54}$ Ayia Triada, Gournia, Khania, Knossos, Mallia, Phaistos, Kea, Samothrace, and Zakros. Our roundel is highly unusual, however, in having a linear inscription on both faces (including a new Linear A sign), and in being stamped around the edges with the impressions of two different sealstones, both of them new and unique additions to the glyptic corpus, and one of them a cushion seal, possibly of gold, carrying a cult scene.

52 This issue was addressed in the comments on Hallager 1990 (supra fn. 3), esp. pp. 145-146.

53 Cf. Hallager (supra fn. 13): 76. M. Perna, "The Roundels of Haghia Triada", Kadmos 33, 1994, 93-141, considers as "valid the possibility that it was the seal owner who shaped the clay pastille" (p. 101). We disagree. If the roundel is a receipt (Hallager, supra fn. 3, p. 133), then it should represent an official substitution for the commodity, and if the roundel remains in the archives (Perna, p. 93), then it is the commodity that has left. In order to impress them, seals have to be removed from the arm of their owner; it then becomes just as possible for the scribe, as for the owner, to use them to impress the roundel; and given the complexity of producing a neat roundel, it makes more sense for the scribe to take charge of the entire process: shaping the roundel, impressing its edges with the seals, and recording the transfer of 5 units of a commodity to two people ( 3 to the owner of the cushion seal and 2 to the owner of the lentoid).

54 Hallager (supra fn. 3): 135 Table 1 lists sites, including Pyrgos, though at the time its status as a producer of roundels was still being debated. The ninth and most recent site is Samothrace: Matsas 1991 (supra fn. 18). 
Now that Pyrgos has produced two tablets and one inscribed roundel, it is probably correct to imagine that some kind of administration was present at the site, even if it depended only on one literate member. ${ }^{55}$ In this light, it should not be overlooked that two signs on our roundel exhibit striking similarities to two signs on the tablet PYR 1, sign 37 on both the roundel and in PYR 1.1, and roundel sign 41 and tablet sign 26. If a scribe were resident at Pyrgos then we can imagine the possibility that Pyrgos originated documents and was not merely the recipient of documents inscribed elsewhere. ${ }^{56}$ Since the architecture and contents of the Pyrgos country house show signs of contact with, and awareness and even imitation of, developments at major centers such as Knossos, ${ }^{57}$ then it might not be too much to conclude that literacy during LM I B was a fairly widespread phenomenon, existing not only at palaces and in the larger towns, but also in the smaller centers like Pyrgos. ${ }^{58}$

55 In Aegean Seals (supra fn. 3), Weingarten cautions (p. 112) that the tablets and seal impressions "prove some literacy at the site, but they do not prove an active bureaucracy". With the addition of our roundel, an active bureaucracy at Pyrgos becomes more plausible.

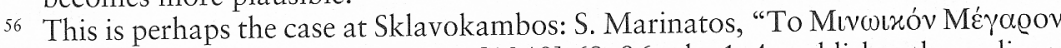

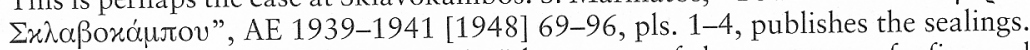
According to him the sealings come in "three types of clay: most are of a fine, red or buff clay; a few are pale, the rest gray and fine". And J. Betts, "New Light on Minoan Bureaucracy", Kadmos 6, 1967, 15-40, identifies Sk HMs 611, 612, $613-624,625,628,629$ as of a yellow-orange clay. With such a diversity of clay types it seems likely that most, if not all, of the Sklavokambos sealings derived from elsewhere: HMs 612-624 were impressed by the same ring as Pigorini Mus. 71971 from Ayia Triada and as HMs 102 (a nodulus) from Gournia (Betts figs. 6 and 7); HMs 625-627 were impressed by the same ring as KZ 12 (Betts fig. 4) and as AT 125 (added by Weingarten); HMs 628 and 629 were impressed by the same ring as HMs 101 (a nodulus) from Gournia (Betts figs. 2 and 3); and HMs $632-$ 635 were impressed by the same ring as HMs 516a from Ayia Triada (AT 117; Betts fig. 5); and HMs 642a, b, d and HMs 643 carry impressions of seals that seem to have been created at Kato Zakro (J. Weingarten, The Zakro Master and his Place in Prehistory, SIMA Pocketbook 26, 1983, p. 88 fn. 3, and 109).

57 Pyrgos exhibits palatial, and especially Knossian, connections: extensive use of ashlar masonry and gypsum, the importation of pots such as the Marine Style vases probably of Knossian manufacture, a Cycladic jug of a type known on Crete only at Knossos (Cadogan [supra fn. 5] figs. 29, 28, 19, respectively), Egyptian stone vase fragments, and a faience conch shell (compare the related example from Shaft Grave III at Mycenae, C. Baurain and P. Darcque, "Un triton en pierre à Malia”, BCH 103, 1983, 3-73, esp. 73).

58 P. Rehak and J. G. Younger, "Architectural and Administrative Change in Neopalatial Crete", AJA 100, 1996 (forthcoming abstract). 